\title{
Voices of Mother's Interaction with Midwives in Natural Childbirth: A Qualitative Study
}

\author{
Firoozeh Mirzaee Rabor ${ }^{1}$, Ali Taghipour ${ }^{2}$, Khadigeh Mirzaii Najmabadi ${ }^{*}$ \\ ${ }^{1}$ Department of Midwifery, School of Nursing and Midwifery, Mashhad University of Medical Science, \\ Mashhad, Iran \\ ${ }^{2}$ Department of Epidemiology, School of Health, Mashhad University of Medical Science, Mashhad, Iran \\ Email: Mirzaeef891@mums.ac.ir, TaghipourA@mums.ac.ir,
}

Received 30 December 2014; accepted 17 January 2015; published 22 January 2015

Copyright (C) 2015 by authors and Scientific Research Publishing Inc.

This work is licensed under the Creative Commons Attribution International License (CC BY). http://creativecommons.org/licenses/by/4.0/

(c) (i) Open Access

\begin{abstract}
Interaction between mothers and midwives during natural childbirth is one of the important factors in relationship between mothers and midwives in natural childbirth. In this qualitative study we explored experiences of mothers and midwives in interaction with each other in natural childbirth. This study was a part of a larger study which was carried out in Iran in 2013-2014. A total of 23 participants participated in this study. 12 primiparous and multiparous women planned to have natural deliveries and 11 midwives were purposefully included for semi-structured in-depth interviews in this study. For analysis and interpretation of mothers' and midwives' experience, conventional content analysis was used. Data were coded in MAXqda software (version 2). Interaction between mothers and midwives could be organized and categorized in one theme "relationship". This theme consists of two subthemes: "respect for the mother" and "interaction" and five categories: "Feeling confidence, Feeling satisfaction, Associated with sensory relationship, Understanding mother's situation, Understanding the meaning of interaction". Good relationship between mothers and midwives in natural childbirth could improve the experience of natural childbirth for mothers. This experience could increase woman's tendency toward natural birth instead of cesarean section in future pregnancies. Findings of this study can be seen as a challenge for health care professionals and policy makers to upgrade care of natural childbirth based on women's preferences and needs.
\end{abstract}

\section{Keywords}

Natural Childbirth, Relationship, Interaction, Qualitative Study, Content Analysis

\footnotetext{
"Corresponding author.
} 


\section{Introduction}

Childbirth is a major event for a mother, which affects her dignity for many years [1]. Parturition is a personal and emotional experience and is a significant lifetime event; women should have the possibility to have a good birth experience [2]. Optimal experience of childbirth induces an increase in breastfeeding rate, promotes mother's and her family's mental health and leads to fewer complications for them.

Studies have shown that respect for mother's dignity in childbirth is the main factor for a positive childbirth experience [3] [4]. Respect for patients' dignity is a cornerstone of medical ethics and nurses have a key role in respecting patients' dignity [5].

Despite the introduction of numerous theories about the concept of autonomy during the last decade, there is no consensus regarding the nature of autonomy. Concept of dignity can vary from culture to culture and in different social contexts [6]. Mother's autonomy in childbirth means that the mother can make her own informed decision about interventions [7]. The principle of autonomy necessitates respect for maternal wishes and choices [8]. However, the first step in respecting women's wishes and needs is appropriate communication between women and health providers.

Mothers should be encouraged to accept responsibility for childbirth and to be active in decision-making in maternity care during labor [9]. It has also been shown that women want a sense of security and want to feel involved in decisions affecting them during childbirth, which entails good interaction between women and midwives during childbirth [10]. Contact and communication between the midwife and her client is based on the key concept that birth is a physiological process and, in principle, can therefore take place without features such as pregnancy-related factors, complications, expectations, pain, the form of organizational care and support, all of which influence women's experience of childbirth [11] [12]. Therefore, the main factor for a positive childbirth experience is good relationship with women in order to support them [13].

Midwives have a key role in natural childbirth [14]. Midwives have the responsibility to respect mothers' dignity and improve their health. Therefore, midwives should respect mothers' decision-making process by providing the necessary information [15]. International Medical Association (IMA) expressed that patients not only have right to receive necessary medical information, but they have right to choose appropriate treatment from all the available treatments or interventions [16].

Women's dignity plays an important role in improving safety and decision-making, but it should be developed within the background of a trusting interaction between women, health professionals and health systems [17]. One way to enhance women's confidence in and satisfaction with childbirth is to make sure they understand what is happening to them [18].

Many studies have emphasized on the importance of control and necessary information given as main keys to positive birth experience and both of these are mediated through professional careers [19]. In short, both quantitative and qualitative studies agree that the presence and role of birth professionals are basic to both birth outcomes and birth experience [20].

For all women, however, finding autonomy in birth requires access to safe modes of delivery that are appropriate to their personal and social circumstances and their values and sense of integrity and dignity, and also circumstances that enable them to consider themselves as the primary agents of their own birthing process [21].

Sociological studies have suggested that decision-making processes are the result of equilibrium of power between women, midwives and obstetricians.

Despite the fact that many studies have addressed delivery processes, only a few studies have evaluated the relationship between mother and midwife in natural childbirth.

Interaction between mothers and midwives has an important role in midwifery care and midwives have a key role in such interactions. Therefore, it is important to know how interaction between midwives and mothers is formed. The qualitative study is the best way to answer this question. Therefore, we interviewed a group of mothers and midwives to determine their opinions about this interaction.

\section{Methods}

\subsection{Study Location and Participants}

This study was undertaken from April 2013 until May 2014 in three university hospitals and two private hospital labor wards and the participant's homes in two province capitals in Iran, Kerman and Mashhad. Kerman is a tra- 
ditional city while Mashhad is a religious city. Kerman and Mashhad have around 534,441 and 3,009,295 inhabitants, respectively, based on latest national census.

Iranian women who had natural childbirth in university and private hospitals and midwives who worked in these centers were invited to participate in this study. The women (both primiparous and multiparous) and midwives (with different experience) included in this study. They spoke Farsi very well.

Midwives and women who did not speak Farsi, or they were reluctant to participant in the study or had problems during pregnancy or delivery were excluded from the study.

\subsection{Study Design}

In this study a qualitative method was used. Conventional content analysis was employed in this study with an aim to discover, describe and define humane interactions between women and midwives in natural child birth. Qualitative interview enables the interviewer to maintain focus on the issue at hand and facilitate rapport [22] [23].

\subsection{Study Procedures}

Permission to conduct and tape-record the interviews was obtained (in writing) from each woman and midwife in three university and two private hospitals. They were assured that all the information would be treated confidentially. The women and midwives participating in this study provided verbal consent and they indicated the time and place of interview; then they provided informed consent. Each participant was interviewed by one interviewer (FM), who is a midwife researcher with a good experience in the childbirth setting. Purposeful sampling with maximum variation was used. The semi-structured in depth interviews were conducted in the subject's home and in hospitals; the interview lasted between 45 and 60 minutes. For one woman the second interview was conducted. The initial question from each mother was "Can you tell me about the experience of relationship with midwives during labor and delivery in the hospital?" and the initial question from each midwife was "Can you tell me about the experience of relationship with women during labor and delivery in the hospital?" The women and midwives were encouraged to describe all their feelings and experiences by probe questions. Probing questions were asked during the discussion. Sampling was continued until data saturation.

Written narratives were found to be the most suitable data collection method for the present study in order to encourage the midwives and women to describe their experience of interactions with each others in the hospital.

\subsection{Data Analysis}

Data was analyzed qualitatively using content analysis, guided by Graneheim and Ludman (2004). First, the transcribed text was read for several times to get a general sense of the issue. Meaning units, i.e. the main phrases in the text, were identified, condensed and specified.

Codes were given to each meaning unit. Data were coded in MAXqda software (version 2) by a member of the research team (FM). Then the codes were compared and classified into subcategories.

Comparisons were made continuously and integrated into sub-themes and one pervasive theme. A preliminary analysis was performed by the first author independently, and then was repeated by KM, AT. Conflicts and disagreements were resolved by consensus.

\subsection{Validity of the Study}

Validity of this study was achieved by prolonged engagement in understanding of meaning units. Credibility in this study was achieved by member checking. We took the final report to the participants and asked if they felt the results were a true and accurate reflection of their experiences. Dependability was achieved by peer check strategies. Confirmability was documented by asking a colleague to follow the path and comment on the conclusions. The study was transferable as the results were sensible for midwives and women other than the ones participated in this study.

\subsection{Ethical Considerations}

This study was approved by Research Ethics Committee of Mashhad University of Medical Sciences, Mashhad, 
Iran. All the participants were aware of the aim of the study, the confidentiality of their interviews and their right to participate and withdraw any time they wished.

\section{Results}

\subsection{Study Population}

A total of 12 women and 11 midwives participated in this study. The women were 18 - 43 years of age. To make ensure of maximum variation, the participants were selected from various parities, ages, educational levels and socio-economic backgrounds in order to get diversity in experiences, perceptions and beliefs. Five women had one delivery, four women had two deliveries, two women had three deliveries, and one woman had four deliveries. Six women had some high school education, three women had BA degrees, two women had MA degrees, and one had $\mathrm{PhD}$. Seven women had natural delivery in university hospitals and five women had natural delivery in private hospitals. The midwives were 22 - 53 years of age, with job experiences ranging from 1 to 34 years. Seven midwives had BA degree in midwifery; three had MA in midwifery; and one midwife had $\mathrm{PhD}$ in reproductive health. Eight midwives worked in university hospitals and three worked in private hospitals.

\subsection{A Theme on Relationship}

A theme "relationship" consists of two sub-themes from the midwives' and women's experiences about relationship with each other during labor. Each sub-theme describes different perspectives in the process of relationship (Table 1). "Respect for the mother" points to midwives' and women's explanations about respect for mother during labor for better relationship, while the sub-theme "interaction" refers to midwives' and women's experiences about understanding mother's status and is associated with sensory relationship and body language for mothers. The emergence of the theme "relationship" is shown in Table 1.

Respect for Mother

The women and midwives wished to have a good relationship through respect for mothers. Respect for mother's values, religion and attitudes are important keys to the relationship between women and midwives.

The women and midwives in this study knew that self-esteem of the mother induces respect for the mother. They described mother's self-confidence in labor is the main factor to achieve respect for mother.

The women and midwives knew that giving hope to the mother during labor is very important in enhancing mother's self-confidence. For example a woman (31 years old, first delivery, W5) in this regard said:

"She (midwife) gave me comfort... She said the pain will be over, you're going to give birth, I also... I was confident about these words, I was hopeful..."

Table 1. "Relationship"-a theme on interaction between women and midwives during labor and natural birth.

\begin{tabular}{|c|c|c|c|}
\hline Theme & Sub-theme & Category & Subcategory \\
\hline \multirow{5}{*}{ Relationship } & & Feeling confidence & $\begin{array}{l}\text { - Hope for the mother } \\
\text { - } \text { Reducing maternal worries } \\
\text { - Encouraging mothers to have natural delivery }\end{array}$ \\
\hline & Respect for mother & Feeling satisfaction & $\begin{array}{l}\text { - Maintain mother's privacy } \\
\text { - Maternal satisfaction because of the response } \\
\text { - Maternal satisfaction with proper treatment } \\
\text { with the newborn }\end{array}$ \\
\hline & \multirow{3}{*}{$\begin{array}{l}\text { Interaction between midwives } \\
\text { and women }\end{array}$} & $\begin{array}{l}\text { Associated with } \\
\text { sensory relationship }\end{array}$ & $\begin{array}{l}\text { - Not confining the mother to bed } \\
\text { - Appropriate body language } \\
\text { - Intimacy to facilitate communication }\end{array}$ \\
\hline & & $\begin{array}{l}\text { Understanding } \\
\text { mother's situation }\end{array}$ & $\begin{array}{l}\text { - Control of maternal health } \\
\text { - To help mother }\end{array}$ \\
\hline & & $\begin{array}{l}\text { Understanding the } \\
\text { meaning of interaction }\end{array}$ & $\begin{array}{l}\text { - Appropriate treatment in interaction } \\
\text { - Slowly and patiently answering questions with } \\
\text { women }\end{array}$ \\
\hline
\end{tabular}


The midwives and women described how reducing maternal concerns about labor enhances maternal self-esteem. A woman (38 years old, second delivery, W9) said:

"I was worried,... I was afraid of labor pains, I was afraid of causing problems for me or the fetus,... but the midwife came beside me. She started talking to me; with her talking she gave me comfort and reduced my concerns".

The midwives knew that reducing maternal concerns during labor is very important to continue the labor process. The expression of one midwife (39 years old, with 10 years of work experience, M7) reveals this meaning. "They (women) are worried when they enter the ward. It is necessary, to speak to them, I talk with the mother... I ask why they are worried. I explain to them,... I guess with this work they become less worried."

Maintaining women's privacy in labor, when the midwives want to examine their vagina, is important. The women explained respect for mother's privacy is a key factor for maternal satisfaction, the following expression of woman (42 years old, third delivery, W12) reveals this concept.

"She (midwife) took me all around the partitions, when she (midwife) wanted to carry out vaginal examination... she was allowed, and explained to me the reason for the examination... I was happy with her behavior."

A majority of women and midwives underscored the importance of responding to women's requests during labor for the relationship with women. For instance, a woman (34 years old, first, delivery, W10) said:

"I was thirsty... I wanted water, I told her (midwife) to bring water. She brought me a glass of water... she began to talk to me."

Interaction between Midwives and Women

Three factors relate to interaction between midwives and women: 1) Midwives assist women through sensory relationship and body language; 2) They understand mother's situation; 3) They understand the meaning of interaction between women and midwives.

Women wish to be free of bed; they wish to walk to the ward, eat and drink...

A woman (40 years old, third delivery, W6) in this regard said:

"Seems like I was tied to a bed...I could not move, I could not eat anything. I was connected to devices. There was nobody next to my bed that I could speak to..."

The midwives believed that not confining the mother to bed is very good for the mother's interaction with midwives.

Appropriate body language affected the interaction between women and midwives; when women were asked how they interacted with midwives, they said midwives' facial expressions and smile helped them have better interaction. A woman (39 years old, second delivery, W5) described:

"I was afraid to ask her (midwife),... She had a serious and furious face. I did not ask any questions."

Midwives believed kindness facilitates communication between women and midwives.

The following expression (41 years old, with 18 years of work experience M9) reveals this meaning.

"Sometimes, I do not do anything special for her (woman), but I smile... I feel, with this smile, she (woman) tells me about her needs easier."

The women felt that the control of mother's health means that midwives understand the mother's situation. Controlling mother's labor pain, bleeding, fever and blood pressure are important for their interaction with midwives. A woman (40 years, third delivery, M11) said:

"I was constantly monitored; she (midwife) controlled my blood pressure and the heart rate of the fetus; she asked me, 'how is your pain?'... overall, she understood my situation..."

All the women and midwives believed that appropriate behavior toward the mother is the key to a good relationship with women. A woman (30 years old, first delivery, W8) said:

"She (midwife) treated me well,... she spoke kindly to me. She was joking with me... I was happy with her behavior."

\section{Discussion}

This study highlights how interaction is formed between women and midwives during natural delivery. The findings of this study show that in traditional and religious cities, interaction between women and midwives in natural delivery is formed by "relationship"

In the technologic era of obstetrics, it has been difficult for midwives to promote normal processes of reproduction, especially labor, when intravenous therapy, continuous electronic fetal monitoring, episiotomy, and, in 
some centers, epidural anesthesia, are accepted as almost routine practices [24].

The relationship between the patient and health care professionals are influenced by administrative policies from several sources that may become the focus of ethical issues and deliberations for either a particular patient or for many patients [25].

According to the findings of this study, good interaction between midwives and women is crucial for women's ability to follow the flow of the labor process. Several studies have emphasized that good interaction is essential for women during labor [26] [27]. Berg et al., too, have stressed women's unique need for support during birth, and they should be seen as individuals for a trusting relationship [28].

A good relationship between women and midwives in delivery improves the trust of the mother in her health providers so that they will have better cooperation with midwives and other health care providers, consistent with the findings of other studies in this field [29] [30].

One of the techniques to improve women's autonomy in childbirth is the use of appropriate communication with them. Respect for autonomy is the first principle of medical ethics, which enhances their health.

A trusting relationship can be achieved by good interaction and proper behavior. A good quality of the proper interaction can also promote women's feelings and relationship with her child [31] [32]. Goodman et al. described that a positive childbirth experience increases first-time mothers' self-confidence and leads to positive expectations for future childbirth experiences [33].

One of the issues raised in this study is the small number of midwives and the large number of women with labor in the hospitals; therefore, midwives are busy at ward, and it is a barrier factor for good interaction between midwives and women.

The proportion of a country's GNP is devoted to the health system and women and children's health affects the number of personnel providing service to women during childbirth. Lack of trained midwives in childbirth centers disrupts relationship between women and midwives [34]. Furthermore, the midwives in this study required better education on the interaction with women in delivery.

The main strength of this study was investigated of interaction details between women and midwives in natural child birth, which it has been less attention in other studies.

Although the findings of the qualitative research studies cannot be generalized to other communities, there are some ways for providing acceptability and objectivity for data and increasing the accuracy of data used, which can help apply these results for similar communities, that we call validity of the study.

\section{Conclusion}

The findings of this study showed the importance of relationship between mothers and midwives during natural delivery. Good relationship in natural delivery could induce a positive experience from delivery for women, and this experience could decrease cesarean section rate.

\section{Acknowledgements}

The researchers appreciate all the women and midwives who participated in this study. This project is a part of fulfillment for a $\mathrm{PhD}$ degree in reproductive health and has been supported by Mashhad University of Medical Sciences, Mashhad, Iran [code: 920487]. The authors are grateful for financial support provided by the university.

\section{Conflicts of Interests}

The authors declare that they have no conflicts of interest to disclose.

\section{References}

[1] Simkin, P. (1992) Just Another Day in a Woman's Life? Part II: Nature and Consistency of Women's Long-Term Memories of Their First Birth Experiences. Birth, 9, 64-81. http://dx.doi.org/10.1111/j.1523-536X.1992.tb00382.x

[2] Thomson, A. (2003) The Relationship of the Legalisation of Midwifery and Safe Motherhood. Midwifery, 19, 77-78. http://dx.doi.org/10.1016/S0266-6138(03)00017-2

[3] Goodman, P., Mackey, M.C. and Tavakoli, A.S. (2004) Factors Related to Childbirth Satisfaction. Journal of Advanced Nursing, 46, 212-219. http://dx.doi.org/10.1111/j.1365-2648.2003.02981.x 
[4] Gibbins, J. and Thomson, A.M. (2001) Women’s Expectations and Experiences of Childbirth. Midwifery, 17, $302-313$. http://dx.doi.org/10.1054/midw.2001.0263

[5] Rahmani, A., Ghahramanian, A. and Alahbakhshian, A. (2010) Respecting to Patients' Autonomy in Viewpoint of Nurses and Patients in Medical-Surgical Wards. Iranian Journal Nursing and Midwifery Research, 15, 14-19.

[6] Van Thiel, G.J. and van Delden, J.J. (2001) The Principle of Respect for Autonomy in the Care of Nursing Home Residents. Nursing Ethics, 8, 419-431. http://dx.doi.org/10.1177/096973300100800506

[7] Waelpu, A.J.M. (2001) Het perspectief van verloskundigen: Voorlichting over Voorlichting (The Perspective of Midwives: Information about Information). Tijdschrift voor Verloskundigen (Journal for Midwives), 10, 114-117. (In Dutch)

[8] Chigbu, C.O. and Onyeka, T.C. (2011) Denial of Pain Relief during Labor to Parturients in Southeast Nigeria. International journal of Gynecology, 114, 226-228. http://dx.doi.org/10.1016/j.ijgo.2011.04.006

[9] Levy, V. (1999) Protective Steering: a Grounded Theory Study of the Processes by Which Midwives Facilitate Informed Choices during Pregnancy. Journal of Advanced Nursing, 29, 104-112. http://dx.doi.org/10.1046/j.1365-2648.1999.00867.x

[10] Wahn, E.H., Nissen, E. and Ahlberg, B.M. (2005) Becoming and Being a Teenage Mother: How Teenage Girls in South Western Sweden View Their Situation. Health Care Women International, 26, 591-603. http://dx.doi.org/10.1080/07399330591004917

[11] Van der Hulst, L.A.M. (1999) Dutch Midwives: Relational Care and Birth Location. Health and Social Care in the Community, 7, 242-247. http://dx.doi.org/10.1046/j.1365-2524.1999.00184.x

[12] Smeenk, A.D.J. and Ten Have, H.A.M. (2003) Medicalization and Obstetric Care: An Analysis of Developments in Dutch Midwifery. Medicine, Health Care and Philosophy, 6, 153-165. http://dx.doi.org/10.1023/A:1024132531908

[13] Hodnett, E.D. (1999) Caregiver Support for Women during Childbirth. Update Software, Oxford.

[14] Kirkham, M. (2004) Informed Choice in Maternity Care. Palgrave Macmillan, Basingstoke.

[15] Rocha, S.M.M. and Lima, R.A.G. (2000) Understanding Nursing: The Usefulness of a Philosophical Perspective. Nursing Philosophy, 1, 50-56. http://dx.doi.org/10.1046/j.1466-769x.2000.00015.x

[16] Ballou, K.A. (1998) A Concept Analysis of Autonomy. Journal of Professional Nursing, 14, 102-110. http://dx.doi.org/10.1016/S8755-7223(98)80038-0

[17] Madi, B.C. and Crow, R. (2003) A Qualitative Study of Information about Available Options for Childbirth Venue and Pregnant Women’s Preferences for a Place of Delivery. Midwifery, 19, 328-336.

[18] Fleissig, A. (1999) Are Women Given Enough Information by Staff during Labour and Delivery? Midwifery, 9, 70-75. http://dx.doi.org/10.1016/0266-6138(93)90049-X

[19] Halldorsdottir, S. and Jourldottir, S. (1996) Journeying through Labour and Delivery: Perceptions of Women Who Have Giving Birth. Midwifery, 12, 46-61. http://dx.doi.org/10.1016/S0266-6138(96)90002-9

[20] Hodnett, E. (1998) Continuity of Care Giver during Pregnancy and Child Birth. Birth, 27, 218.

[21] Kukla, R., Kuppermann, M., Little, M., Lyerly, A.D., Mitchell, L.M., Armstrong, E.M. and Harris, L. (2009) Finding Autonomy in Birth. Bioethics, 23, 1-8. http://dx.doi.org/10.1111/j.1467-8519.2008.00677.x

[22] Kvale, S. (1996) Interviews-An Introduction to Qualitative Research Interviewing. SAGE Publications, London.

[23] Morse, J.M. and Field, P.A. (1995) Qualitative Research Methods for Health Professionals. SAGE Publications, London.

[24] Rooks, J.P. (1997) Midwifery and Childbirth in America. Temple University, Philadelphia, 295-343.

[25] Elizabeth, S., Sharp, C.N.M. and Facnm, F. (1998) Ethics in Reproductive Health Care: A Midwifery Perspective. Journal of Nurse-Midwifery, 43, 235-245. http://dx.doi.org/10.1016/S0091-2182(98)00011-1

[26] Walsh, D. (1999) An Ethnographic Study of Women's Experience of Partnership Caseload Midwifery: The Professional as a Friend. Midwifery, 15, 165-176. http://dx.doi.org/10.1016/S0266-6138(99)90061-X

[27] Bowers, B.B. (2002) Mother's Experiences of Labor Support: Exploration of Qualitative Research. Journal of Obstetetric, Gynecological and Neonatal Nursing, 31, 511-521. http://dx.doi.org/10.1177/0884217502239218

[28] Berg, M., Lundgren, E., Hermansson, E. and Wahlberg, V. (1996) Women's Experience of the Encounter with the Midwife during Childbirth. Midwifery, 12, 11-15. http://dx.doi.org/10.1016/S0266-6138(96)90033-9

[29] Lavender, T., Walkinshaw, S.A. and Walton, I. (1999) A Prospective Study of Women’s Views of Factors Contributing to a Positive Birth Experience. Midwifery, 15, 40-46. http://dx.doi.org/10.1016/S0266-6138(99)90036-0

[30] Waldenström, U. (1999) Experience of Labour and Birth in 1111 Women. Journal of Psychosomatic Research, 47, 471-482. http://dx.doi.org/10.1016/S0022-3999(99)00043-4 
[31] Price, S., Noseworthy, J. and Thornton, J. (2007) Women’s Experience with Social Presence during Childbirth. The American Journal of Maternal/Child Nursing, 32, 184-191.

[32] Ekstrom, A. and Nissen, A. (2006) A Mother's Feelings for Her Infant Are Strengthened by Excellent Breastfeeding Counseling and Continuity of Care. Pediatrics, 118, 309-314. http://dx.doi.org/10.1542/peds.2005-2064

[33] Goodman, P., Mackey, M.C. and Tavakoli, A.S. (2004) Factors Related to Childbirth Satisfaction. Journal of Advanced Nursing, 46, 212-219. http://dx.doi.org/10.1111/j.1365-2648.2003.02981.x

[34] Bauer, S. and Kotter, C. (2013) Midwife-Led Birth Centers: An Alternative to Hospital Child Birth? Neonatal, 217, 1423. 
Scientific Research Publishing (SCIRP) is one of the largest Open Access journal publishers. It is currently publishing more than 200 open access, online, peer-reviewed journals covering a wide range of academic disciplines. SCIRP serves the worldwide academic communities and contributes to the progress and application of science with its publication.

Other selected journals from SCIRP are listed as below. Submit your manuscript to us via either submit@scirp.org or Online Submission Portal.
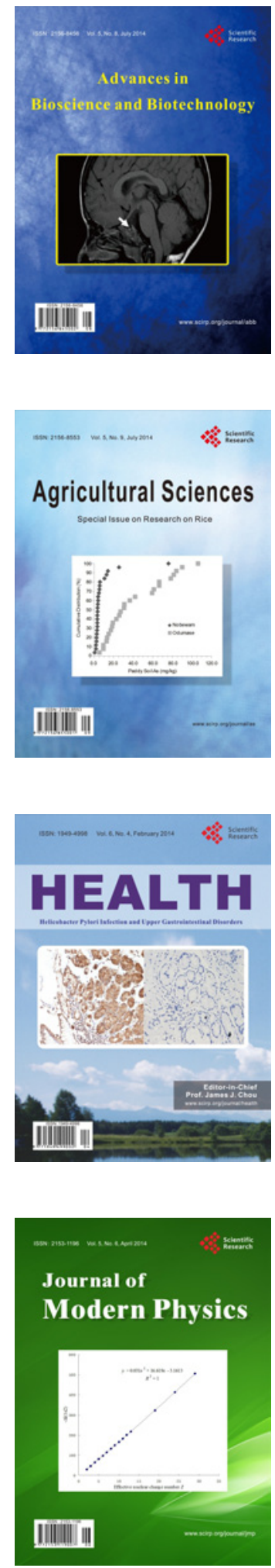
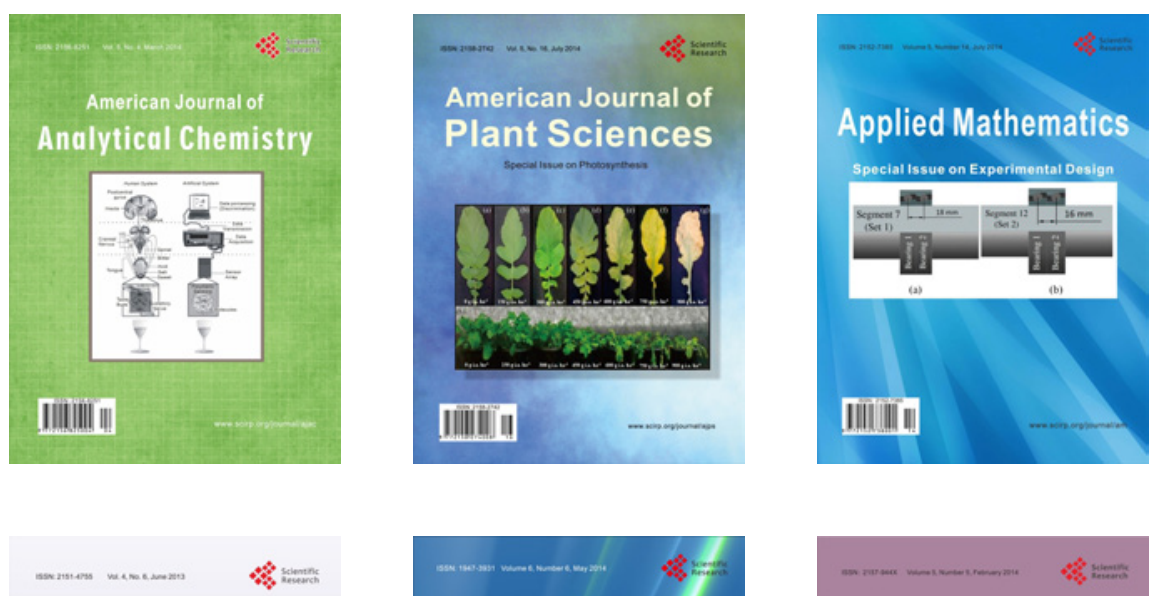

Creative Education
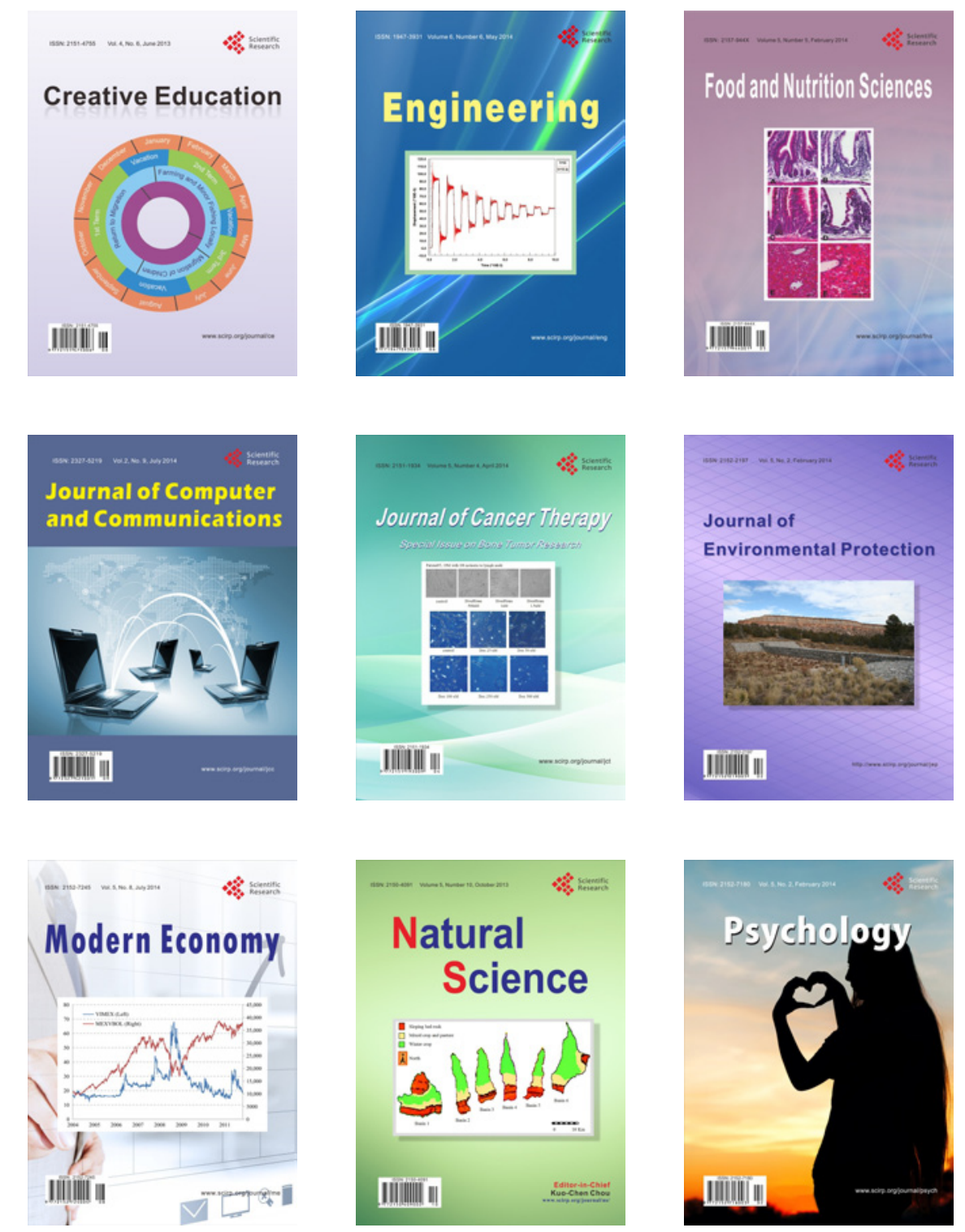